\title{
GAMBARAN PENGETAHUAN PENCABUTAN GIGI SISWA SMA NEGERI 1 SANG TOMBOLANG KABUPATEN BOLAANG MONGONDOW
}

\author{
${ }^{1}$ Joandri P. Dandel, \\ ${ }^{2}$ Ni Wayan Mariati \\ ${ }^{2}$ Jimmy Maryono
${ }^{1}$ Kandidat Skripsi Program Studi Pendidikan Dokter Gigi Fakultas Kedokteran
${ }^{2}$ Program Studi Pendidikan Dokter Gigi Universitas Sam Ratulangi Manado
E-mail: jdandel180@gmail.com

\begin{abstract}
Tooth extraction is one of the actions that are often done in the field of dentistry. Tooth extraction is done with an indication of severely damaged teeth and can not be manage. Most people visit the dentist after their teeth are badly damaged, and eventually have to be onderwent tooth extraction. That is caused by lack of public knowledge about the importance of maintaining healthy teeth and mouth. This study aimed to obtain the students' knowledge of tooth extraction in SMA 1 Tombolang Bolaang Mongondow. This was a descriptive study with a cross sectional design. There were 51 samples obtained by using Slovin formula. The results showed that most students in SMA Negeri 1 Tombolang Bolaang Mongondow had moderate knowledge about tooth extraction.
\end{abstract}

Keywords: tooth extraction, knowledge

\begin{abstract}
Abstrak: Pencabutan gigi merupakan salah satu tindakan yang sering dilakukan di bidang kedokteran gigi. Pencabutan gigi dilakukan dengan indikasi gigi yang rusak parah dan tidak bisa dirawat. Sebagian besar masyarakat berkunjung ke dokter gigi setelah gigi rusak parah, dan akhirnya harus dilakukan tindakan pencabutan gigi. Hal ini dapat disebabkan oleh kurangnya pengetahuan masyarakat tentang pentingnya memelihara kesehatan gigi dan mulut. Penelitian ini bertujuan untuk mendapatkan gambaran pengetahuan pencabutan gigi siswa SMA Negeri 1 Sang Tombolang Kabupaten Bolaang Mongondow. Jenis penelitian yang digunakan yaitu deskriptif dengan desain potong lintang. Jumlah sampel sebanyak 51, diperoleh dengan menggunakan rumus Slovin. Hasil penelitian menunjukkan tingkat pengetahuan siswa tentang pencabutan gigi di SMA Negeri 1 Sang Tombolang sebagian besar memiliki pengetahuan sedang.
\end{abstract}

Kata kunci: pencabutan gigi, pengetahuan

Pengetahuan merupakan informasi atau maklumat yang diketahui dan disadari oleh seseorang setelah melalui pengamatan inderawi. Pengetahuan dapat membentuk perilaku seseorang dan diwujudkan melalui tindakan. Demikian juga dalam hal pemeliharaan kesehatan gigi dan mulut, dibutuhkan pengetahuan yang baik agar terhindar dari berbagai jenis penyakit yang disebabkan oleh masalah gigi dan mulut.

Pengetahuan tentang kesehatan gigi dan mulut dapat diperoleh melalui berbagai jenis sumber informasi, salah satunya yaitu penyuluhan kesehatan gigi dan mulut yang bertujuan untuk mengurangi angka kehilangan gigi serta penyakit gigi dan mulut lainnya.

Menurut RISKESDAS tahun 2013 
melaporkan bahwa skor DMF-T di Indonesia mencapai 4,85 atau 5 gigi yang diperkirakan mengalami karies, atau dicabut karena karies. Hal tersebut menunjukkan bahwa masih kurangnya kesadaran masyarakat tentang pemeliharaan kesehatan gigi dan mulut. ${ }^{1}$ Berdasarkan penelitian yang dilakukan di BP-RSGM Manado Sulawesi Utara pada tahun 2012 mengenai tindakan pencabutan gigi tetap, diperoleh hasil terdapat 1389 kasus pencabutan gigi dengan frekuensi sebesar 41,2\%. Hasil tersebut menunjukkan bahwa hampir setengah dari subjek yang diteliti memiliki pengalaman pencabutan gigi. $^{2}$

Berdasarkan survei awal di SMA Negeri 1 Sang Tombolang Maelang Kabupaten Bolaang Mongondow yang telah dilakukan, sekolah tersebut memiliki jumlah siswa kelas $\mathrm{X}$ sebanyak 60 siswa, kelas XI sebanyak 25 siswa, dan kelas X sebanyak 20 siswa. Peneliti tertarik untuk mengadakan penelitian di sekolah ini, karena letaknya di daerah terpencil yaitu di desa Maelang, dan di sekolah tersebut belum pernah dilakukan penelitian.

\section{BAHAN DAN METODE PENELITIAN}

Penelitian ini menggunkan metode deskriptif dengan pendekatan potong lintang. Penelitian ini dilakukan di SMA Negeri 1 Sang Tombolang Desa Maelang Kabupaten Bolaang Mongondow pada bulan Desember 2014.

Populasi penelitian diambil dari siswa kelas X, XI, dan XII SMA Negeri 1 Sang Tombolang Desa Maelang. Jumlah siswa kelas X yaitu 60 siswa, kelas XI 25 siswa, dan kelas XII 20 siswa.

Sampel ditentukan dengan kriteria inklusi (sehat fisik dan mental; bersedia untuk menjadi sampel dalam pengambilan data), dan juga kriteria eksklusi (tidak hadir pada saat penelitian dilaksanakan; tidak kooperatif pada saat pengambilan data). Perhitungan besar sampel minimal dalam penelitian ini menggunakan Rumus Slovin, dan didapat sampel sebanyak 51 orang.
Sampel diambil dengan menggunakan teknik purposive random sampling.

Variabel yang digunakan dalam penelitian ini ialah pengetahuan pencabutan gigi, yaitu pengetahuan siswa yang dilihat dengan menggunakan kuesioner. Kuesioner berisi sepuluh pertanyaan yang berhubungan dengan pengetahuan pencabutan gigi. Pengukuran dalam kuesioner ini menggunakan skala Guttman. Skala ini menggunakan beberapa pertanyaan dengan merespon dua pilihan jawaban yaitu $\mathrm{A}=$ tahu, $\mathrm{B}=$ tidak tahu. Pilihan jawaban A diberi skor 2, dan jawaban B diberi skor 1 . Nilai tertinggi : 2 x $10=20$. Nilai terendah : 1 x $10=10$. Kategori penilaian pengetahuan dibagi dalam 3 kategori yaitu: pengetahuan kurang $=$ skor penilaian 10, pengetahuan sedang $=$ skor penilaian 15, pengetahuan baik = skor penilaian 20.

Alat ukur yang digunakan yaitu kuesioner serta alat tulis menulis yang digunakan pada saat pengisian kuesioner. Pengambilan data terbagi 2. Data primer yaitu data yang diperoleh melalui kuesioner. Data sekunder yaitu data yang diperoleh dari profil sekolah berupa data jumlah siswa dari SMA Negeri 1 Sang Tombolang. Pengolahan data yang diperoleh diolah menggunakan program komputer Microsoft Exel dan disajikan dalam bentuk tabel distribusi frekuensi.

\section{HASIL PENELITIAN}

Subyek dalam penelitian berjumlah 51 responden dengan karakteristik dikelompokkan berdasarkan jenis kelamin, usia, dan kelas. Karakteristik subyek penelitian berdasarkan jenis kelamin yaitu siswa lakilaki sebanyak 20 orang $(39,2 \%)$ dan perempuan sebanyak 31 orang (60,8\%). Karakteristik subyek penelitian berdasarkan usia yaitu siswa usia 15 tahun sebanyak 18 orang (35,2\%), 16 tahun sebanyak 22 orang (43,3\%), 17 tahun sebanyak 11 orang (21,5\%). Karakteristik subyek penelitian berdasarkan kelas yaitu siswa kelas $\mathrm{x}$ sebanyak 17 orang (33,3\%), kelas XI 
sebanyak 19 orang (37,3\%), kelas XII sebanyak 15 orang $(29,4 \%)$.

Hasil penelitian yang telah dilakukan menunjukkan bahwa, siswa kelas $\mathrm{X}$ dengan pengetahuan baik sebanyak 8 siswa, pengetahuan sedang 8 siswa, dan pengetahuan kurang 1 siswa. Kelas XI dengan pengetahuan baik sebanyak 10 siswa, pengetahuan sedang sebanyak 9 siswa, dan pengetahuan kurang tidak ada. Siswa kelas XII dengan pengetahuan baik sebanyak 4 siswa, pengetahuan sedang sebanyak 10 siswa, pengetahuan kurang 1 siswa (Tabel 1).

Tabel 1. Distribusi gambaran pengetahuan pencabutan gigi pada siswa SMA Negeri 1 Sang Tombolang

\begin{tabular}{cccccc}
\hline \multirow{2}{*}{ Pengetahuan } & \multicolumn{3}{c}{ Kelas } & \multirow{2}{*}{$\%$} & \multirow{2}{*}{ X } \\
& XI & XII & & \\
\hline Baik & 8 & 10 & 4 & 22 & 43,1 \\
Sedang & 8 & 9 & 10 & 27 & 52,9 \\
Kurang & 1 & 0 & 1 & 2 & 4 \\
Total & 17 & 19 & 15 & 51 & 100 \\
\hline
\end{tabular}

Pada penelitian ini, pengetahuan siswa tentang pencabutan gigi diukur menggunakan alat ukur kuesioner yang terdiri dari 10 pertanyaan. Berdasarkan pertanyaan nomor 1 , siswa kelas $X$ yang menjawab tahu sebanyak 14 orang $(82,4 \%)$ dan tidak tahu 3 orang (17\%); siswa kelas XI yang menjawab tahu sebanyak 7 orang (36,8\%) dan tidak tahu 12 orang (63\%); dan siswa kelas XII yang menjawab tahu sebanyak 12 orang (80\%) dan tidak tahu 3 orang (20\%).

Tabel 2. Distribusi pengetahuan siswa tentang pencabutan gigi yang tidak boleh dilakukan pada penderita penyakit jantung, pertanyaan nomor 1

\begin{tabular}{cccccc}
\hline \multirow{2}{*}{ Kelas } & \multirow{2}{*}{ Sampel } & \multicolumn{2}{c}{ Tahu } & \multicolumn{2}{c}{ Tidak Tahu } \\
& & $\mathrm{n}$ & $\%$ & $\mathrm{n}$ & $\%$ \\
\hline $\mathrm{X}$ & 17 & 14 & 82,4 & 3 & 17,6 \\
XI & 19 & 7 & 36,8 & 12 & 63,2 \\
XII & 15 & 12 & 80 & 3 & 20 \\
Jumlah & 51 & 33 & 66,4 & 18 & 33,6 \\
\hline
\end{tabular}

Berdasarkan pertanyaan nomor 2, siswa kelas $\mathrm{X}$ yang menjawab tahu sebanyak 12 orang $(70,6 \%)$ dan tidak tahu 5 orang $(29,4 \%)$, siswa kelas XI yang menjawab tahu sebanyak 11 orang $(57,9 \%)$ dan tidak tahu 8 orang (42,1\%), siswa kelas XII yang menjawab tahu sebanyak 12 orang (80\%) dan tidak tahu 3 (20\%).

Tabel 3. Distribusi pengetahuan siswa tentang pencabutan gigi yang tidak boleh dilakukan pada penderita penyakit diabetes mellitus, pertanyaan nomor 2

\begin{tabular}{cccccc}
\hline \multirow{2}{*}{ Kelas } & \multirow{2}{*}{ Sampel } & \multicolumn{2}{c}{ Tahu } & \multicolumn{2}{c}{ Tidak Tahu } \\
& & $\mathrm{n}$ & $\%$ & $\mathrm{n}$ & $\%$ \\
\hline $\mathrm{X}$ & 17 & 12 & 70,6 & 5 & 29,4 \\
XI & 19 & 11 & 57,9 & 8 & 42,1 \\
XII & 15 & 12 & 80 & 3 & 20 \\
Jumlah & 51 & 35 & 69,5 & 16 & 30,5 \\
\hline
\end{tabular}

Berdasarkan pertanyaan nomor 3, siswa kelas $\mathrm{X}$ yang menjawab tahu sebanyak 9 orang $(52,9 \%)$ dan tidak tahu 8 orang $(47,1 \%)$, siswa kelas XI yang menjawab tahu sebanyak 5 orang (26,3\%) dan tidak tahu 14 orang (73,7\%), siswa kelas XII yang menjawab tahu sebanyak 9 orang (60\%) dan tidak tahu 6 orang (40\%).

Tabel 4. Distribusi pengetahuan siswa tentang pencabutan gigi yang tidak boleh dilakukan pada saat seseorang mengalami tekanan darah tinggi, pertanyaan nomor 3

\begin{tabular}{cccccc}
\hline \multirow{2}{*}{ Kelas } & \multirow{2}{*}{ Sampel } & \multicolumn{2}{c}{ Tahu } & \multicolumn{2}{c}{ Tidak Tahu } \\
& & $\mathrm{n}$ & $\%$ & $\mathrm{n}$ & $\%$ \\
\hline $\mathrm{X}$ & 17 & 9 & 52,9 & 8 & 47,1 \\
XI & 19 & 5 & 26,3 & 14 & 73,7 \\
XII & 15 & 9 & 60 & 6 & 40 \\
Jumlah & 51 & 23 & 46,4 & 28 & 53,6 \\
\hline
\end{tabular}

Berdasarkan pertanyaan nomor 4, siswa kelas $\mathrm{X}$ yang menjawab tahu sebanyak 5 orang $(29,4 \%)$ dan tidak tahu 12 orang (70,6\%), siswa kelas XI yang menjawab tahu sebanyak 14 orang $(73,7 \%)$ dan tidak tahu 5 orang (26,3\%), siswa kelas XII yang menjawab tahu sebanyak 8 orang (53,3\%) dan tidak tahu 7 orang $(46,7 \%)$. 
Dandel, Mariati, Maryono: Gambaran pengetahuan pencabutan...

Tabel 5. Distribusi pengetahuan siswa tentang penggunaan gigi palsu merupakan salah satu perawatan setelah pencabutan gigi, pertanyaan nomor 4

\begin{tabular}{cccccc}
\hline \multirow{2}{*}{ Kelas } & \multirow{2}{*}{ Sampel } & \multicolumn{2}{c}{ Tahu } & \multicolumn{2}{c}{ Tidak Tahu } \\
& & $\mathrm{n}$ & $\%$ & $\mathrm{n}$ & $\%$ \\
\hline X & 17 & 5 & 29,4 & 12 & 70,6 \\
XI & 19 & 14 & 73,7 & 5 & 26,3 \\
XII & 15 & 8 & 53,3 & 7 & 46,7 \\
Jumlah & 51 & 27 & 52,2 & 24 & 47,8 \\
\hline
\end{tabular}

Berdasarkan pertanyaan nomor 5, siswa kelas $\mathrm{X}$ yang menjawab tahu sebanyak 12 orang $(70,6 \%)$ dan tidak tahu 5 orang $(29,4 \%)$, siswa kelas XI yang menjawab tahu sebanyak 17 orang $(89,5 \%)$ dan tidak tahu 2 orang (10,5\%), siswa kelas XII yang menjawab tahu 13 orang $(86,7 \%)$ dan tidak tahu 2 orang (13,3\%).

Tabel 6. Distribusi pengetahuan siswa tentang pencabutan gigi dengan tindakan operasi dilakukan pada gigi geraham yang posisinya sangat miring, pertanyaan nomor 5

\begin{tabular}{cccccc}
\hline \multirow{2}{*}{ Kelas } & \multirow{2}{*}{ Sampel } & \multicolumn{2}{c}{ Tahu } & \multicolumn{2}{c}{ Tidak Tahu } \\
& & $\mathrm{n}$ & $\%$ & $\mathrm{n}$ & $\%$ \\
\hline X & 17 & 12 & 70,6 & 5 & 29,4 \\
XI & 19 & 17 & 89,5 & 2 & 10,5 \\
XII & 15 & 13 & 86,7 & 2 & 13,3 \\
Jumlah & 51 & 42 & 82,3 & 9 & 17,7 \\
\hline
\end{tabular}

Berdasarkan pertanyaan nomor 6, siswa kelas $\mathrm{X}$ yang menjawab tahu sebanyak 3 orang $(17,6 \%)$ dan tidak tahu 14 orang (82,4\%), siswa kelas XI yang menjawab tahu sebanyak 1 orang $(5,3 \%)$ dan tidak tahu 18 orang (94,7\%), siswa kelas XII yang menjawab tahu sebanyak 5 orang $(33,3 \%)$ dan tidak tahu 10 orang (66,7\%) (Tabel 7).

Berdasarkan pertanyaan nomor 7, kelas $\mathrm{X}$ yang menjawab tahu sebanyak 3 orang $(17,6 \%)$ dan tidak tahu 14 orang $(82,4 \%)$, siswa kelas XI yang menjawab tahu sebanyak 1 orang $(5,3 \%)$ dan tidak tahu 18 orang (94,7\%), siswa kelas XII tang menjawab tahu sebanyak 6 orang (40\%) dan tidak tahu 9 orang (60\%) (Tabel 8).
Tabel 7. Distribusi pengetahuan siswa tentang pencabutan gigi yang sudah rusak parah lebih baik dari pada membiarkannya, pertanyaan nomor 6

\begin{tabular}{cccccc}
\hline \multirow{2}{*}{ Kelas } & \multirow{2}{*}{ Sampel } & \multicolumn{2}{c}{ Tahu } & \multicolumn{2}{c}{ Tidak Tahu } \\
& & $\mathrm{n}$ & $\%$ & $\mathrm{n}$ & $\%$ \\
\hline $\mathrm{X}$ & 17 & 3 & 17,6 & 14 & 82,4 \\
XI & 19 & 1 & 5,3 & 18 & 94,7 \\
XII & 15 & 5 & 33,3 & 10 & 66,7 \\
Jumlah & 51 & 9 & 18,7 & 42 & 81,3 \\
\hline
\end{tabular}

Tabel 8. Distribusi pengetahuan siswa tentang pencabutan gigi dapat menjaga kesehatan gigi dan mulut, pertanyaan nomor 7

\begin{tabular}{cccccc}
\hline \multirow{2}{*}{ Kelas } & \multirow{2}{*}{ Sampel } & \multicolumn{2}{c}{ Tahu } & \multicolumn{2}{c}{ Tidak Tahu } \\
& & $\mathrm{n}$ & $\%$ & $\mathrm{n}$ & $\%$ \\
\hline $\mathrm{X}$ & 17 & 3 & 17,6 & 14 & 82,4 \\
XI & 19 & 1 & 5,3 & 18 & 94,7 \\
XII & 15 & 6 & 40 & 9 & 60 \\
Jumlah & 51 & 10 & 21 & 41 & 79 \\
\hline
\end{tabular}

Berdasarkan pertanyaan nomor 8, kelas $\mathrm{X}$ yang menjawab tahu sebanyak 7 orang (41,2\%) dan tidak tahu 10 orang (58,8\%), siswa kelas XI yang menjawab tahu sebanyak 3 orang $(15,8 \%)$ dan tidak tahu 16 orang $(84,2 \%)$, siswa kelas XII yang menjawab tahu sebanyak 6 orang (40\%) dan tidak tahu 9 orang (60\%).

Tabel 9. Distribusi pengetahuan siswa tentang pencabutan gigi yang tidak boleh dilakukan saat gigi dalam keadaan sakit/infeksi, pertanyaan nomor 8

\begin{tabular}{cccccc}
\hline \multirow{2}{*}{ Sampel } & \multirow{2}{*}{ Kelas } & \multicolumn{2}{c}{ Tahu } & \multicolumn{2}{c}{ Tidak Tahu } \\
& & $\mathrm{n}$ & $\%$ & $\mathrm{n}$ & $\%$ \\
\hline 17 & $\mathrm{X}$ & 7 & 41,2 & 10 & 58,8 \\
19 & $\mathrm{XI}$ & 3 & 15,8 & 16 & 84,2 \\
15 & $\mathrm{XII}$ & 6 & 40 & 9 & 60 \\
51 & Jumlah & 16 & 32,3 & 35 & 67,7 \\
\hline
\end{tabular}

Berdasarkan pertanyaan nomor 9, kelas $\mathrm{X}$ yang menjawab tahu sebanyak 5 orang (29,4\%) dan tidak tahu 12 orang (70,6\%), siswa kelas XI yang menjawab tahu sebanyak 8 orang $(42,1 \%)$ dan tidak tahu 11 orang (57,9\%), siswa kelas XII yang menjawab tahu sebanyak 7 orang $(46,7 \%)$ dan tidak tahu 8 orang (53,3\%). 
Tabel 10. Distribusi pengetahuan siswa tentang salah satu komplikasi pencabutan gigi yaitu pendarahan, pertanyaan nomor 9

\begin{tabular}{cccccc}
\hline \multirow{2}{*}{ Kelas } & \multirow{2}{*}{ Sampel } & \multicolumn{2}{c}{ Tahu } & \multicolumn{2}{c}{ Tidak Tahu } \\
& & $\mathrm{n}$ & $\%$ & $\mathrm{n}$ & $\%$ \\
\hline $\mathrm{X}$ & 17 & 5 & 29,4 & 12 & 70,6 \\
$\mathrm{XI}$ & 19 & 8 & 42,1 & 11 & 57,9 \\
XII & 15 & 7 & 46,7 & 8 & 53,3 \\
Jumlah & 51 & 20 & 39,4 & 31 & 60,6 \\
\hline
\end{tabular}

Berdasarkan pertanyaan nomor 10 , siswa kelas $\mathrm{X}$ yang menjawab tahu sebanyak 10 orang $(58,8 \%)$ dan tidak tahu 7 orang (41,2\%), siswa kelas XI yang menjawab tahu sebanyak 10 orang (52,6\%) dan tidak tahu 9 orang $(47,4 \%)$, siswa kelas XII yang menjawab tahu sebanyak 5 orang (33,3\%) dan tidak tahu 10 orang (66,7\%).

Tabel 11. Distribusi pengetahuan siswa tentang gigi susu yang masih bertahan dalam rongga mulut harus dicabut jika sudah waktunya tanggal, agar gigi tetap tumbuh dengan baik, pertanyaan nomor 10

\begin{tabular}{cccccc}
\hline \multirow{2}{*}{ Kelas } & \multirow{2}{*}{ Sampel } & \multicolumn{2}{c}{ Tahu } & \multicolumn{2}{c}{ Tidak Tahu } \\
& & $\mathrm{n}$ & $\%$ & $\mathrm{n}$ & $\%$ \\
\hline $\mathrm{X}$ & 17 & 10 & 58,8 & 7 & 41,2 \\
XI & 19 & 10 & 52,6 & 9 & 47,4 \\
XII & 15 & 5 & 33,3 & 10 & 66,7 \\
Jumlah & 51 & 25 & 48,3 & 26 & 51,7 \\
\hline
\end{tabular}

\section{BAHASAN}

Hasil penelitian menunjukkan bahwa kelas X sebanyak 14 siswa, kelas XI sebanyak 7 siswa dan kelas XII sebanyak 12 siswa yang mengetahui bahwa pencabutan gigi tidak boleh dilakukan pada penderita penyakit jantung. Pada pertanyaan pencabutan gigi yang tidak boleh dilakukan pada penderita diabetes menunjukkan bahwa, masih terdapat beberapa siswa dari kelas X sampai XII yang menjawab tidak tahu yaitu sebanyak 16 siswa (31,4\%). Sedangkan pada pertanyaan pencabutan gigi yang tidak bisa dilakukan pada penderita darah tinggi (hipertensi) juga masih kurang, yaitu siswa kelas X sampai XII yang menjawab tahu hanya 23 siswa (45\%), dan yang tidak tahu sebanyak 28 siswa $(54,9 \%)$

Peneliti melihat dari hasil penelitian menunjukkan bahwa masih banyak siswa yang belum mengetahui tentang kontra indikasi pada pencabutan gigi. Penulis berasumsi bahwa hal ini disebabkan karena kurangnya informasi yang yang diperoleh para siswa baik secara langsung melalui sosialisasi-sosialisasi dari instansi kesehatan setempat mengenai kesehatan gigi dan mulut khususnya tentang kontraindikasi pencabutan gigi. Selain faktor tersebut, kurangnya pemahaman siswa dapat juga disebabkan oleh beberapa hal, diantaranya rasa ingin tahu dari siswa yang masih kurang, ataupun masih minimnya pengetahuan yang diperoleh baik dari lingkungan keluarga, sekolah, atau melalui media cetak atau elektronik, serta kurangnya motivasi dari orang tua. Hal ini didukung oleh pendapat dari Prayitno dalam Riduwan (2009), yang menyatakan bahwa motivasi belajar tidak saja merupakan suatu energi yang menggerakkan siswa untuk belajar, tetapi juga sebagai sesuatu yang mengarahkan aktivitas siswa kepada tujuan belajar. ${ }^{3} \mathrm{Hal}$ tersebut sejalan dengan penelitian yang dilakukan oleh Dian Anisawati di Kabupaten Tulungagung tentang Hubungan Kondisi dan Penggunaan Sarana dan Prasarana Pendidikan dengan Keefektifan pembelajaran di SMK Negeri SeKabupaten Tulungagung. Dalam penelitiannya disebutkan bahwa sarana dan prasarana merupakan salah satu faktor kemajuan pendidikan, dan dapat dijadikan tolak ukur penentu arah dan tujuan pendidikan. $^{4}$

Dari penelitian yang telah dilakukan pada siswa kelas X sampai XII, sebanyak 27 siswa (52\%) yang menjawab tahu tentang gigi palsu merupakan salah satu perawatan yang dilakukan setelah pencabutan gigi. Hasil tersebut cukup baik karena lebih dari setengah siswa telah mengetahui tentang salah satu perawatan yang dilakukan setelah pencabutan gigi. 
Hal ini dapat disebabkan karena adanya informasi yang diperoleh para siswa baik dari lingkungan masyarakat tempat mereka tinggal maupun melalui media-media informasi lainnya, bahwa gigi yang sudah dicabut dapat digantikan dengan gigi palsu. Berdasarkan penelitian yang dilakukan oleh Bayu pada tahun 2014 di desa Molompar Utara kabupaten Minahasa Utara, memperoleh hasil bahwa sebagian besar responden (57\%) mengetahui gigi palsu dapat menggantikan gigi yang hilang akibat pencabutan berdasarkan informasi yang mereka dapatkan melalui lingkungan tempat tinggal mereka maupun mediamedia informasi lainnya. ${ }^{5}$

Dalam penelitian ini diperoleh hasil yaitu, 42 siswa (82,3\%) menjawab tahu tentang pencabutan gigi dengan operasi dilakukan pada gigi geraham yang posisinya sangat miring. Hasil tersebut sudah cukup baik, walaupun masih ada beberapa siswa yang belum mengetahui tentang pencabutan gigi dengan operasi dilakukan pada gigi geraham. Peneliti berpendapat bahwa, hal ini karena pada anak usia sekolah terutama anak SMA biasanya gigi molar ketiga mulai tumbuh, sehingga siswa cukup mengetahui tentang penanganan gigi geraham yang harus dioperasi jika posisinya sangat miring. Hal tersebut bisa dihubungkan dengan penelitian yang dilakukan oleh Hattab, dari Fakultas Kedokteran Gigi di Yordania, menemukan bahwa 33,6\% pada subjek penelitian yang berusia 18-20 tahun mengalami gigi terpendam. Hasil tersebut menunjukkan bahwa cukup banyak anak usia sekolah khususnya SMA, yang mengalami kasus erupsi gigi molar ketiga yang terpendam (impaksi) sehingga harus dilakukan tindakan operasi (odontektomi). ${ }^{6}$

Dalam penelitian ini menunjukkan hasil yang kurang baik tentang pengetahuan siswa mengenai mencabut gigi yang rusak lebih baik dari pada membiarkannya, yaitu hanya 9 siswa $(17,7 \%)$ dari siswa kelas $X$ sampai XII yang menjawab tahu. Hal tersebut menunjukkan bahwa masih kurangnya kesadaran siswa tentang pentingnya memelihara kesehatan gigi dan mulut. Dapat dilihat dari data hasil SKRT tahun 2004, prevalensi karies gigi di Indonesia mencapai 90,05\%. Berdasarkan hasil dari RISKESDAS Nasional tahun 2007 melaporkan bahwa skor DMF-T di Indonesia mencapai 4,85 atau masuk dalam kategori buruk. $^{7}$ Hasil tersebut menggambarkan bahwa masih kurangnya perhatian masyarakat, khususnya anak usia sekolah dalam pemeliharaan kesehatan gigi dan mulut.

Pengetahuan siswa tentang pencabutan gigi yang sudah rusak atau berlubang dapat menjaga kesehatan gigi dan mulut dalam penelitian ini menunjukkan hasil yaitu, sebanyak 10 siswa (19,6\%) yang menjawab tahu dan 40 siswa $(78,4 \%)$ lainnya menjawab tidak tahu. Berdasarkan hasil tersebut, dapat dilihat bahwa masih kurangnya pengetahuan siswa tentang kesehatan gigi dan mulut. Hal inilah yang menyebabkan masih tingginya prevalensi karies gigi masyarakat di Indonesia, khususnya pada anak usia sekolah karena tidak mengetahui bahwa gigi yang sudah rusak apabila dicabut, dapat menjaga kesehatan gigi dan mulut bahkan kesehatan tubuh.

Pengetahuan siswa tentang pencabutan gigi yang tidak boleh dilakukan saat gigi dalam keadaan sakit atau infeksi juga menunjukkan hasil yang kurang, yaitu hanya 16 siswa (31,8\%) yang menjawab tahu, dan 35 siswa ( 68,6\%) yang menjawab tidak tahu. Penulis berpendapat bahwa, sebagian besar siswa hanya sebatas mengetahui bila gigi yang sudah rusak dan terasa sakit sebaiknya segera dicabut agar rasa sakit dapat segera hilang, tanpa mengetahui akibatnya. Salah satu akibat yang bisa terjadi saat dilakukan pencabutan pada gigi yang sedang sakit atau infeksi yaitu perdarahan yang terus menerus. Dalam penelitian ini, yang mengetahui tentang perdarahan merupakan salah satu komplikasi pencabutan gigi yaitu sebanyak 20 siswa (39,2\%), dan yang tidak tahu 
sebanyak 31 siswa (60,78\%). Di bidang kedokteran gigi, seperti yang telah diketahui bahwa menghindari terjadinya komplikasi terhadap tindakan yang dilakukan merupakan salah satu tugas penting yang harus diketahui.

Pengetahuan siswa tentang gigi susu yang masih bertahan dalam rongga mulut harus dicabut jika sudah waktunya tanggal, agar gigi tetap tumbuh dengan baik menunjukkan hasil yang juga masih kurang, karena setengah dari jumlah siswa dari kelas X sampai XII menjawab tidak tahu. Penulis berpendapat bahwa, sebagian besar siswa yang tidak mengetahui hal tersebut dapat diakibatkan oleh karena kurangnya rasa ingin tahu dari siswa itu sendiri. Pengetahuan seorang anak juga dipengaruhi oleh motivasi orang tua, karena lingkungan terdekat yaitu keluarga. Orang tua diharapkan dapat memberikan motivasi terhadap anak dalam hal mencari tahu atau menambah pengetahuan sebanyak mungkin, salah satunya yaitu pengetahuan tentang pencabutan gigi atau kesehatan gigi dan mulut secara menyeluruh. Dengan demikian, diharapkan dapat meningkatkan derajat kesehatan gigi dan mulut yang lebih baik.

\section{SIMPULAN}

Pengetahuan tentang pencabutan gigi pada siswa SMA Negeri 1 Sang Tombolang Maelang Kabupaten Bolaang Mongondow yaitu dengan pengetahuan baik sebanyak 43,1\%, sedang sebanyak $52,9 \%$, dan kurang sebanyak $4 \%$.

\section{SARAN}

1. Masyarakat: Diperlukan upaya dalam peningkatan pengetahuan tentang kesehatan gigi dan mulut, salah satunya yaitu tentang pencabutan gigi yang dapat diperoleh melalui informasi di media cetak atau elektronik serta sumber informasi lainnya.

2. Institusi pendidikan: Perlu diadakannya penyuluhan atau sosialisasi terhadap masyarakat, khususnya di daerah pedesaan yang kurang mendapat informasi mengenai pentingnya mengetahui dan memelihara kesehatan gigi dan mulut.

3. Peneliti: Diharapkan dapat menjadi tolak ukur kualitas pengetahuan siswa tentang pencabutan gigi, serta dapat menyusun konsep sosialisasi atau penyuluhan yang lebih baik agar dalam penelitian tingkat lanjut tentang pengetahuan pencabutan gigi pada siswa yang apabila nanti dilakukan akan lebih baik lagi.

\section{DAFTAR PUSTAKA}

1. Anonymous. Badan penelitian dan pengembangan kesehatan Departemen RI. laporan hasil Riset Kesehatan Dasar (RISKESDAS). Jakarta. 2013. p. 140-41.

2. Ngangi R.S. Gambaran pencabutan gigi di Balai Pengobatan Rumah Sakit Gigi dan Mulut. [online]. Accesed: desember 2014. Available from URL: http://e-ournal.unsrat.ac.id/index.php/ egigi/article. 2012.

3. Prayitno. Motivasi belajar. Jakarta: IKIP Padang. 2009. p. 93.

4. Anisawati D. Hubungan kondisi dan penggunaan sarana dan prasarana pendidikan dengan keefektifan pembelajaran di SMK Negeri SeKabupaten Tulungagung. SKRIPSI. FIP UM. 2011. 17

5. Warouw B. Gambaran tingkat pengetahuan dan sikap masyarakat tentang pencabutan gigi di desa Molompar Utara Kabupaten Minahasa Tenggara. SKRIPSI. PSPDG Universitas Sam Ratulangi. Manado. 2013. p. 32.

6. Putri NA. Prevalensi odontektomi molar tiga rahang bawah. SKRIPSI. Departemen Bedah Mulut RSGMP USU. 2012. p. 52.

7. Anonymous. Hasil survei kesehatan rumah tangga. Departemen Kesehatan RI. Jakarta. 2004. p. 116. 